\title{
Enactivism and Freedom Education
}

Qing Li

College of Education

Towson University

${ }^{*}$ li[]towson.edu

Received November 2013; accepted September 2014; published Autumn 2014.

\section{Ian Winchester}

Faculty of Education

University of Calgary

\begin{abstract}
In this paper, we argue, grounded on empirical evidence, that enactivism is a promising philosophical stance with great potential to address challenges brought by our rapidly changing world. We then propose Freedom Education, a new form of teaching and learning founded on the enactivist theory. After discussing what constitutes Freedom Education and what it is not, we recommend several principles to establish a learning world of freedom education.
\end{abstract}

Keywords: Enactivism; Education; Freedom Education; Cognition; Learninng.

\section{Our world is changing}

We live in a changing world. In his book titled Exodus to the Virtual World, Castronova (2007) describes how millions and millions of people are migrating to virtual worlds. People, for instance, immerse in a collective fantasy in massive multiuser online environments. In such a fantasy world, they may see or even build anything, whether a stately palace, a magnificent castle, or a peaceful landscape with ocean views. They may also see and interact, through typing, texting, talking, with other characters who can be either machine run (i.e. controlled by the system's artificial intelligence engines) non-player characters or avatars controlled by other human beings. They can do various trivial or odd things ranging from blacksmithing to practicing yoga skills in this virtual world just as if they were in a real world. Called "virtual worlding," such an increasingly popular practice signifies that these people have immigrated to the new land of the virtual worlds.

The number of people who have gone off to this virtual frontier is growing rapidly. For example, Second Life (SL) is a virtual world developed by Linden Lab and launched in 2003. The office SL website claims (Second Life 2013) that SL gives free membership and allows users, called residents, to interact, explore, meet others, socialize, participate in activities, create, do business, or travel throughout the world. Since its launching, over 36 million accounts 
were created with more than a million people visiting SL each month. In a similarly vein, according to the Wikipedia, over seven million subscribed to the World of Warcraft as of July, 2013. World of Warcraft has the highest number of subscribers of a Massively Multiplayer Online Role Playing Game (MMORPG) which gives it the Guinness World Record of the most popular MMORPG (World of Warcraft, n.d.). Minecraft is another virtual game world which many people inhabit. As of 2013, over 12,554, 000 people had bought the game (Minecraft 2013). While the numbers for these sorts of virtual worlds may rise and fall, new worlds are constantly emerging online.

At first glance, the spreading of the population in virtual worlds may seem trivial. However, as Castronova (2007) points out, the sheer quantity of people who spend so much time and energy immersed in the virtual worlds has significant impacts on every aspect of our life. For example, "Second Life (SL)" has its own economy and currency, the Linden Dollar, which can be exchanged with US Dollars. The Wikipedia (Economy of Second Life, n.d.) reports the following statistics: about sixty four thousand users made a profit in SL in February 2009. The SL economy grew 65\% in 2009 to US $\$ 567$ million, while the entire US virtual goods market is about $\$ 2.7$ billion US dollars. Although no recent data on this aspect is available, the trend is obvious. Edward Castronova, in his book mentioned above, convincingly argues that our exodus to virtual worlds is forever changing our life both in virtual and real worlds. Such a change is so substantial that our current educational systems are facing serious challenges.

\section{The Emergence of Participatory Culture}

What is more, we are observing the emergence of a participatory culture. Technology advancement allows more opportunities for people to interact, collaborate, create, and share. To see following statistics about Facebook alone (Henrikson 2011): Facebook had 750 million users in 2011, which means one out of nine people in the whole world was using Facebook; The 2010 data show that every 20-minutes, people post close to 6 million wall posts, upload about 3 million photos, and write over 10 million messages on this social media site.

The significance and consequence of these developments are difficult to estimate at the current stage. Yet, most of us will agree that new technologies, especially the emergence of Web 2.0 tools, are changing our life fundamentally. Web 2.0 is a "perceived ongoing transition of the WWW from a collection of static websites to a full-fledged computing platform serving Web applications for end users” (O’Reilly 2005). 
This trend of more and more people moving from digital consumers to creators means the increased civic engagement in culture, leading scholars (Jenkins et al. 2006) to believe that a participatory culture is emerging. Participatory culture is "a culture with relatively low barriers to artistic expression and civic engagement, strong support for creating and sharing one's creations, and some type of informal mentorship whereby what is known by the most experiences is passed along to novices. A participatory culture is also one in which members believe their contributions matter, and feel some degree of social connection with one another" (Jenkins et al. 2006: 3).

In a participatory culture, development of the 21st century skills, collaborative learning, creative expression of cultural diversity are placed at a premium (Jenkins et al. 2006). Access to this participatory culture, these authors argue, becomes a new hidden curriculum. Consequently, this brings significant challenges to education.

\section{The Challenge of Participatory Culture and Virtual Worlds to Education}

Whether it is the phenomena of exodus to the virtual world, or the shift towards the participatory culture era, the changes are so fundamental that it forces us to rethink education in principle and the current educational systems in general. As Dede (2008) claims, such fundamental shifts call for the reexamination of education because our traditional views about knowledge, expertise, and learning are being challenged.

Various approaches have been proposed to address such challenges: some scholars suggest improving the existing educational system by modifying current policy and pedagogy to help students develop the $21^{\text {st }}$ century skills (Jenkins et al. 2006); others are more radical by suggesting that we should completely reconsider and redesign our formal educational systems (Dede 2008; Erneling 2010). Important questions such as: how we teach and learn to prepare students to become full participants in our contemporary world, how we are involved in a participatory culture, demand new educational theories and practices.

This paper, therefore, proposes Freedom Education, a new way of creating learning worlds grounded in enactivism. This paper is a further development of our earlier work published in the British Journal of Educational Technology (Li et al. 2010). 


\section{Enactivism and Freedom Education}

Enactivism has recently emerged as a viable framework that provides a more encompassing philosophical stance accounting for learning and creation than other viewpoints (Li et al. 2010; Winn 2006). For example, constructivism, a philosophical viewpoint which has dominated the field of education in the last couple of decades, is grounded in two important perspectives. First, our personal world is one that is socially constructed by us collectively. Second, our personal world is individually constructed in that social context. Enactivism, however, suggests that beyond such constructed worlds, there are many situations in which the world is not constructed by us either collectively or individually, but rather formed out of an interaction between ourselves and our environment in such a way that both ourselves and our environment are transformed.

In this section, we discuss enactivism only briefly due to limited space available. The main idea of the following discussion about enactivism was first published in the British Journal of Educational Technology (Li et al. 2010). To provide readers with more fluid reading, we may or may not use quotation marks. Those who are interested can read our earlier paper (Li et al. 2010) for a detailed articulation of enactivism.

Enactivism has its roots in both phenomenology (Merleau-Ponty 1964a) and biological perspectives (Bateson 1972). On the one hand, enactivism is grounded in Merleau-Ponty's phenomenological view of ontological embodiment, which is based on the idea that "the world which is given in perception...is the concrete, intersubjectively constituted life-world of immediate experience” (Merleau-Ponty, 1964b: xvi). The enactivists' view of doubleembodiment contends that

the world is inseparable from the subject, but from a subject which is nothing but a project of the world, and the subject is inseparable from the world, but from a world which the subject itself projects. (Varela et al. 1991: 7)

Double-embodiment stresses that our body is both a lived structure to experiences and the setting for cognition (Varela et al. 1991). "Mindfulness meditation," a traditional Buddhist idea, has also influenced enactivists' thinking, in which our mind is placed in

embodied everyday experience... [Our reflection] can change from an abstract, disembodied activity to an embodied (mindful), open-ended reflection. By embodied we mean reflection in which body and mind are brought together...[Refection] is not just on experience, but reflection is a form of experience itself and that reflective form of experience can be performed with mindfulness/awareness... (Varela et al. 1991: 27) 
Embodiment is the "developing process" of our interaction with our world, including how we act, do, and perform in order to experience the environment in which we are living. In such a process, our thinking, behaviors, and sensors are all enmeshed and intertwined in helping us making sense of the experience (Johnson 1989).

On the other hand, the biological origin of enactivism includes systems theory and cognitive theory (Michie 2004). Enactivism describes living as systems that produce themselves endlessly (Reid 1995). Under this view, "living systems are not simply observation objects or interacting systems, but rather autonomous, self-contained, self-referencing and self-constructing closed systems" (Maturana \& Varela 1980: v).

The idea that cognition is embodied has been discussed widely and tested with numerous examples and experiments. For instance, recent brain research indicates that the brain has a plasticity never dreamed of several decades ago (Diodge 2007). Before, brains were thought to have a fixed capacity and a limited number of cells and connections. What has been discovered, as explained thoroughly in Diodge's book (2007), is that people can recover completely from devastating strokes through an enactivist program that involves physical exercises as well as thinking about exercises. Such a program of both active physical movements and the mental processes of the movements enables these physical movements to be possible at a later time.

Results from research in both behavioral science and neuro-science demonstrate that some traditionally considered purely symbolic psychological phenomena in fact show perceptual effects (Black et al. 2012). For example, in the 1970s, Black and his team (Black et al. 1979) did an experiment examining the impact of perceptual effect on reading comprehension by asking people to read the following sentences:

1. John was working in the front yard then he went inside.

2. John was working in the front yard then he came inside.

Evidently, sentence one is exactly the same as the sentence two except the word "went" is changed to "came". Yet, the participants took longer time to read the second sentence than the first one. The researchers later discovered that this difference of reading time was caused by the change of perspectives. Apparently, people develop a mental image when reading texts where they visualize in their head, the situation and the people being described. When the word "went" became "came," it changed the spatial perspective in the narrative. People therefore needed to adjust their point of view in their mental image, which resulted in longer reading time and more memory errors (Black et al. 2012). Examples like this demonstrate the inseparability of our body, mind, and the environment, the key idea that enactivism argues for. 
Co-evolvement is an important concept of enactivism, which relates to the idea that cognition is a complex process of systems co-evolving with each other and the environments (Davis et al. 2000). For enactivists, cognitive system is the builder of meaning instead of only a vehicle for processing information (Baerveldt \& Verheggen 1999).

The historical dualist debate considers knowledge either as presentations of reality or as individual agents learner developed inside their "inner-self." Enactivism challenges this debate by considering knowledge to be a domain of possibilities that emerges from "structured coupling" where systems are coeffecting each other in an ever-evolving world (Varela et al. 1991). We believe that knowledge "does not drive the actions of a living system but unfolds in events that evoke these particular actions (Fenwick 2000). Consequently, learners are believed to be an integral part of the context itself. Understanding, therefore, is embedded in action and based on both conscious and non-conscious knowing. Learning is not about gaining information, but an ongoing process of exploration about consciousness, self, context, and interactions of complex systems in order to adapt to the evolving environments" (Li et al. 2010).

The contemporary world in the ordinary sense is relatively stable. For example we have lived in a world with automobiles, telephones, airplanes and the radio for over a hundred years. While small changes have occurred in these things, this last century is arguably the most stable one we have ever had. In contrast to the relatively stable real world, the new virtual world is changing every second. We need not only to be able to keep up with it but also transform it into something better. What follows is the need for a different kind of education that begins with the notion that our world is not only changing rapidly but that we ourselves are too.

We, therefore, suggest that a new form that we term "freedom education," an educational approach grounded in enactivism, can provide solutions to the problems of education that the new virtual environments meld into our traditional ones. We argue that this approach enables us to address the problems we encounter in our current and presently transforming society. Before we delve into that, however, we first discuss the problems of nearly all contemporary learning theories and current educational systems. 


\section{WHAT IS THE PROBLEM?}

In this section, we borrow Erneling's (2010) discussion to briefly describe the basic problems our current educational systems facing without repeatedly citing her work. We start the dialogue from the discussion of two basic ideas, which leads to the introduction of learning theories in computer related contexts. We then argue the need for a paradigm shift and propose "freedom education."

\section{Creativity and Learning Theories}

What is learning and what is the focus of learning theories? The Wikipedia defines learning as "acquiring new, or modifying and reinforcing, existing knowledge, behaviors, skills, values, or preferences” (Learning, n.d. para. 2). Most, if not all, contemporary learning theorists would agree that they mostly care about how learners change in their cognitive ability (i.e. can move beyond information provided) and such a change is not merely caused by chemical or physiological change, rote memorization, or mindless repetition. In addition, learning is not about creativity (Erneling 2010).

Let's compare two students Jason and John: Jason can remember the Pythagorean theorem and is able to regurgitate it. Yet, he flounders when asked to apply this theorem to solve any problems beyond the examples given. John, on the other hand, can solve new problems applying the theorem in new contexts. Therefore, John, but not Jason, has learned the Pythagorean Theorem because he can go beyond what is given-demonstrating a cognitive ability change.

Erneling (2010) asserts that while learning is all about using knowledge to solve new problems, creativity does not belong to the domain of learning or cognitive development, consequently cannot be explained by learning theories. Significant conceptual or other changes are the hallmark of creativity. "If we were in possession of a theory which could explain and predict radical change, the change predicted would already be present in the theory and just making it explicitly would not count as creativity” (Erneling 2010: 19).

With these two concepts suggested and how they appear to be in conflict, Erneling (2010) discussed how the ideas of productivity and educational framework pose a practical dilemma for educators. In this paper, we focus on the learning theories assumed by dominant pedagogical thinking on computers. 


\section{Learning Theories in Computer Related Contexts}

According to Erneling (2010), a majority of research projects conducted in educational technology, in particular how computers can be used to promote learning seemingly accept the idea that infants learning to talk, walk, interact represents an exemplary learning situation: they are always interested, learning seems painless, and no explicit instruction is needed. This is not only reflected in various theories in the field of educational technology such as Papert's constructionism but more broadly in various learning theories. The view that learning is essentially fun and fun is more important than learning something new has been widespread. This might be termed the standard picture of computer related pedagogy.

She (Erneling 2010) argues that such infantilisation of education largely ignores the various different factors contribute to learning. Such differences include, for example, different cognitive skills and different social situations. As well, infantilised learning assumes that learning of everyday experience is the same as the learning of school subject matter knowledge, yet we know that everyday learning is 'natural' and the other is abstract, symbolic and conventional. Agreeing with Erneling's (2010) view about the problems of infantalization of education, we use her arguments to build our case. In the next 2 sections, we again borrow her ways of discussion focusing on the work of Piaget and Chomsky.

\section{Piaget's Theory}

Piaget's theory, especially his focus on qualitative development of human beings, has a fundamental impact on education. Most of our educational programs and instructional approaches are largely grounded in his idea that learning is most effective when children are developmentally ready. His theories propose that any cognitive change involves assimilation and accommodation. Such fundamental indiscriminative view therefore supports the approach that infant learning can be applied to all learning regardless of age, gender, or culture.

Grounded in the biological perspective, Piaget' theory assumes that all cognitive development are processes of biological adaptation to the environment (Piaget 1967). This fundamental assumption leads to the belief that all learning can mimic infant learning, consequently individualizing and infantilizing education. Piaget's famous cognitive development stage theory proposes that every child goes through four stages: sensory-motor, preoperational, concrete operation, formal operational stages, from simple to complex and from concrete to abstract (Piaget 1967). At the first glance, this appeals contradictory to the infantilisation of education because it differentiates mental structures of different stages. Yet, diving deep down, as 
Erneling (2010) argued, we see his two important points supporting infantilisation of education. First, Piaget's pervasive arguments suggest the intelligence of infants even if they cannot talk or walk. Secondly, his theory stresses that the same basic biological principles rule all cognitive development. That is, the development process follows the same assimilation and accommodation process. Assimilation refers to the process in which new materials are assimilated to our old structures, while accommodating describes that when new information cannot be fit into the old structure, new structure needs to be created to accommodate (Piaget 1967). In summary, the infantilisation of education is inspired by Piaget's theory, which claims that cognitive development processes remain the same regardless of contexts, that infants' learning provides the ideal model for any human learning.

Focusing on the Piaget-inspired view of learning, Erneling (2010) uses Seymour Papert's work of pro-technology research as well as anti-technology studies as examples to demonstrate that both the critics and the advocates of technology share similar assumptions: (1) all learning should be natural, which is equivalent to mastering biological and cognitive skills; (2) infants' learning presents an ideal learning situation. That is, both pro-technology and anti-technology researchers support natural learning. Erneling (2010) criticizes this idea of natural learning. She states that natural learning theories are essentially grounded in the learner's natural or biological, or innate, ability to learn. But what is involved in natural learning? For example, does natural ability develop following specific, law-like patterns with initial inborn instincts, as described by Piaget (Piaget 1980)? Or as Skinner (1974) suggested that the natural ability are open to change?

Another problem is that not everything new (i.e. going beyond experience) is learning. For example, not any random arrangement of variables is mathematics, not every utterance is language, unless they fit in to the norms of the specific cognitive activity. Learning is a normative practice within common frameworks. We are, therefore, limited on what we can go beyond existing experiences to new contexts and new directions. Natural learning theories ignore this issue, or at least do not deal with it explicitly. Instead, children are assumed to have an innate ability to judge and therefore can draw correct information from experience. Yet, we know that what is considered norm/knowledge in one culture may not be considered as norm or knowledge in another culture (Erneling 2010). 


\section{Chomsky's Innatism}

Chomsky is another significant theorist, whose work has had significant impacts on learning theories. Since late 1950s, Chomsky's theories of innate language capacity and universal grammar largely contributed on research related to infant language learning. For Chomsky, who describes his picture as Cartesian, language learning requires very little exposure to language in order for a child to learn to speak and understand an infinite number of grammatical sentences (Chomsky 1966). This is not due to the child having learned an infinite number of sentences, but due to the fact that the child possesses a built in linguistic device that enables her to produce that infinite variety from a few examples of sentences in a language. The role of the environment is merely exposing individuals to limited human activities or providing background knowledge.

Chomsky disagrees strongly with Jean Piaget who does not believe the idea of innateness of mental structures (Piattelli-Palmarini 1994). Despite such disagreement, Erneling (2010) describes how these two share the same fundamental views about mental activity and cognition. For example, they hold the same assumptions and frameworks of mental activities, share the same philosophical view, dismiss empiricist developmental theories, and emphasize the learners' active role in cognitive development. Another significant similarity between Piaget and Chomsky is their shared belief about the biological foundation of all psychological activities and cognitive changes. They consider that all learning, thinking or perception, corresponds to some individual, private psychological activity. Cognitive growth is viewed mainly as an individual endeavor, minimizing the impact of the environment. They argue that what is true for learning in the infant and young child is true throughout the life of a human being. As far as we can see, Ernerling's strictures discussed above apply to both Piaget and Chomsky.

As demonstrated from the above discussion, Ernerling is one author who has seen the problems with contemporary learning theories. In particular she shows how they all essentially offer an account of how learning occurs understood as learning the normative standards and skills that are seen as contemporary ones. But none of these accounts offer anything useful with respect to creativity. Our employment of enactivism as the basis for our freedom education shows on the one hand why it is possible to nonetheless learn the normative standards and skills through the interactive picture offered by enactivism, but on the other hand suggests that at any point in that learning, creativity is necessarily a central part of the possibilities that are present in the context of that freedom. 


\section{FREEDOM EDUCATION}

The difficulties Piaget's and Chomsky's works face in handing the fundamental philosophical problems (Erneling 2010) discussed by Erneling, are compounded by the challenges that education is facing with the confluence both of real and virtual worlds and of the shift to a participant culture mentioned at the outset above. Such difficulties call for new educational paradigms. We propose, therefore in this paper, Freedom Education grounded in enactivism, an emergent philosophical standpoint. Enactivism has been claimed by many, including the present authors, to provide a more embracing theoretical perspective that meets the current challenges (Davis et al. 2008; Li et al. 2010; Winn 2006).

Next, we sketch what freedom education would involve in a general sense, in an attempt to provide the first steps towards the freedom approach to education. While we employ several examples to instantiate our points, a more substantive account would involve moving beyond the scope of this paper.

Freedom education grounded in enactivism first and foremost stresses the significance of our world and our interaction with it. Although we acknowledge the importance of individuals' innate ability to cognition, our proposed Freedom Education differs significantly from both Piaget's viewpoints and Chomsky's standpoint. One of the biggest distinctions is that freedom education regards the environment as essential in cognition. Instead of thinking the environment only plays a subordinate or supplemental role, freedom education emphasizes that we cannot separate any human activity from the environment. Subsequently, our subjectivity, mind, and the environment are subsumed within larger systems rather than one dominating the other.

In freedom education, creativity is placed at the center of learning and related activities. From the Freedom Education's point of view, Chomsky's Cartesian picture (Chomsky 1966) is extended from language learning to learning in general. In this view, one characteristic of human learning is that from limited exposure to human activities of all kinds, most human beings are able to go on to solve an infinite number of similar problems without having to have been exposed to that problem situation and its solution before. This is the basis of human creativity, not only in language use but also in all human activities that have a rule-governed nature to any degree. One example of this is our ability to invent and play, in creative ways, an enormous variety of sports and games. Someone who has learned to play soccer can go beyond just following its rules, and in principle can make a creative advance in the sport spontaneously in an indefinite number of ways as well. This is true in very rule-bound activities like chess and most strikingly in a child's active playing with dolls or crayons. 
The environment is crucial in freedom education such as an individual speaking a new language, or a young person mastering their first one. One only knows that the sentence one has just uttered is both grammatically and cognitively sound when those who have already learned to speak the language show that they understand. Beyond language acquisition, the experience of William Webb Ellis, a rugby player, provides another wonderful example. Webb Ellis was the inventor of rugby football who, when playing soccer with his classmates, picked up the ball and ran with it. What could happen at the time was that his classmates and teachers might have sent him to the principal for breaking the rules. But instead, they accepted what he had done as an innovation that would be useful for their game and adopted it. Such acceptance from the environment thus enabled the innovation (e.g. grab the soccer ball and run with it) to be normalized and therefore be recognized as legitimate knowledge creation. In that sense his innovation was grammatically and cognitively sound. Thus one might say that our enactivist "freedom education" paradigm essentially accepts that there might be biological or mental structures that lie behind human learning, but that these structures can only be exercised to effect if they are compatible with the environment in which they are operating. In a nutshell, Freedom Education accepts the view that cognition is biological and individual as Piaget claimed and at least partially innate (as Chomsky claimed only for language acquisition), but also powerfully social and cultural. The inseparability of mind, body, and the environment means that each aspect is equally important.

Because cognition is innate and biological, Freedom Education calls for an enabling world with a high degree of freedom for learner to explore, to investigate, to take risks, to innovate and to develop. Such a world also should contain built in rich stimuli to guide learners to the possible evolving patterns and to inspire creation. As well, the biological nature of cognition means that "doing" plays an essential role in learning. Physical and mental active enactment with the environment enables learners to uncover and interpret patterns and interactions in the process. There appear to be biological or mental structures that are built in to a human being that will not come in to play unless the environment is taken in to account. Thus freedom education has main requirements: the natural capacities and structures as well as the relation to the environment. Without both of these, learning cannot occur. What does this mean for a classroom? It means that we need to offer both the freedom of the learner to engage their natural powers or structures and such powers or structures must be active in an appropriate environment. This environment includes teachers, other learners and a general learning context.

Equally importantly, since cognition is also social and cultural, Freedom Education demands that such an enabling world contains carefully designed constraints. Such indwelling constraints can guide learners to coevolve with the environment towards a preplanned domain of possibilities. In addition, 
learners are not working in isolation, but rather interact with the world, the people in the world, and the content in the world. As suggested by Erneling (2010), learning and cognition are both afforded and constrained by three sets of conditions: (1) the biological body and brain of the agent, (2) the world where the agent situated, and (3) the content to be learned. The agent's physical body and brain have its special functionality and structure. The world is socially and culturally shaped with varied norms and principles, which is represented in activities like business and lawmaking. The content to be learned is represented in forms like manuscripts, records, movies or games, which are categorized as the "third world" by Popper (Popper 1978).

Freedom Education encourages free observation and free activity relating to tasks recognized by the learner as desirable to engage in or achieve. If a learner wants to be able to hit a top spin forehand in tennis, the learner will watch a variety of tennis players engaging in hitting top spins in the context of practice or a game until s/he feels $\mathrm{s} /$ he has a sense of what is involved. Then, s/he will try it her or himself without constraint or criticism. It is important to note that criticism does not mean the kinds of constructive criticism that provides feedback. We are not arguing against feedback, quite contrarily, we believe appropriate, minimal feedback helps learners enormously. Such feedback should be organically built in into the learning world with rich stimuli guiding learners' acts. Rather, we argue against the destructive criticism that distracts learners and limits learners' free exploration of the world around them. The kinds of minimal feedback needed, in this case, are often the fact that the ball does not go as the learner wanted it to, not the commentary from a coach.

Perhaps the greatest topspin in the history of tennis was that of Bjorn Borg, the five-time Wimbledon champion from Sweden. He practiced his topspin against his garage door for hours with nobody watching until he thought it was good enough. Then he played a game with an opponent and tried it out. Sometimes it worked and sometimes it did not. He went back to the garage door and worked on it again until he felt he had a better grasp of it. Borg's approach to mastering the topspin exemplifies an essential characteristic of "freedom education." In contrast, in a conventional tennis school, he would likely have been given instruction as to how to hold the racket, how to place his feet, how to swing the racket, and so on. As well, he would have practiced with an opponent from the beginning. One can learn topspin that way too, but it will never be a "Bjorn Borg” topspin.

Freedom Education is not new. It has been practiced in Buddhist education for centuries. In some traditions, the Buddhist initiates follow their guru step by step towards enlightenment. This following is not forced, but rather is freely chosen in the manner and at the time that the initiates wish. Enlightenment may or may not happen in the end. But when the initiates are done, they can 
in principle do everything precisely as the guru has demonstrated. This of course carries over into other educational areas where Buddhism in this tradition has had influence. For example in arts, such as playing a musical instrument like an violin or painting in a particular style, the guru works with the student until she or he has learned every location of the finger, every stroke of the bow until all the catalogue of pieces that the guru knows are now known also to the student. Nothing is ever forced. The student either follows or does not follow the guru's lead and works on it on her or his own until s/he is satisfied.

The Buddhist tradition also includes an approach to enlightenment in which explicit teaching is not part of the activities between the guru and the students. The tradition of startling, often associated with both a Chinese and Japanese form of Zen Buddhism, is an example. In this practice, the Buddhist initiate gets an action or a puzzle or a koan. The initiate reacts to this action or puzzle or koan, which may lead to the enlightenment. To some degree, of course, this approach is closer to "freedom education" than the other approaches in that it encourages students to find their own way to the solution of the puzzles, often with the help of a guru with minimal feedback. Both this Buddhist tradition and our emphasis on the enactivist account of education form the foundation of our "freedom education." Freedom Education begins with the notion that learners must find their own way to their learning, though a teacher is always a possible part of that way.

From our present point of view, the most famous example of freedom education in contemporary educational history is the Summerhill school A.S. Neill founded in England in the 1920s that is described in his Summerhill book and other writings. Till now, the Summerhill School is still open and has been well regarded. In 2007, the United Nations recognized the school for its excellence (Neill n.d.). Similarly, Bertrand Russell founded the Beacon School which has adopted a similar educational philosophy. In both these schools, children have been offered educational experiences similar to our envisioned "freedom education." That is, students have the freedom to choose what to learn and how to learn. However, constraints are also offered to make sure that the students have learned a few things important for their future lives. Students learn individually, yet work with one another through democratic activities in which the students discuss with one another and come to an agreement or, if necessary, vote. The schools have also adapted a democratic management approach where everyone has equal right to determine the rules (Lamb \& Readhead 1992).

Not only can we find practices of Freedom Education in traditional Buddhist education in the Far East, or in modern society like the Summerhill School in England, it has also been undertaken recently in order to teach deprived children school subjects. The research project "Hole in the Wall" gives another 
example of what we refer to as Freedom Education. In 1999, Mitra, a professor in India, started to explore the potential of computers for children's learning (Mitra \& Rana 2001). Mitra and his team installed an Internet connected PC (with a hidden camera) in a wall close to an urban slum New Delhi, and left. Nine months later, the team found amazing things: groups of kids were playing on the computer. Their data demonstrated that these kids, who had no formal schooling, self-taught each other how to surf the Internet and use the software by simply playing on the computer. Wondering whether this interesting result was only purely accidental, Mitra's team (Mitra et al. 2005) repeated the experiment in diverse locations. They installed computers with Internet connections in small rural villages, shantytown in urban cities, and remote poor areas in countryside towns. To their surprise, the results were incredibly consistent regardless of the geographic locations, contents to be learned or the student populations: the truth is, students can self-learn any subject by interacting with each other and with the computers. In fact, Mitra and his team discovered that ethnic minority children who had no prior biology background knowledge learned biology, children who did not know any English learned English, only through their self-monitored and selfregulated learning from a computer. Their experiments also included a comparison between regular school learning and this self-instruction approach, or Freedom Education. The results? The freedom education was as effective as any traditional formal classroom learning. More importantly, such freedom learning processes also helped improve students' social values and collaborative skills (Mitra \& Dangwal 2010; Mitra et al. 2005).

These examples, from historic Buddhist education originating from the Far East, to the Summerhill school in England, to the "Hole in the Wall" project in India, may make you wonder what can happen when North American children learn school subjects from freedom education. If we rewind the time back to late 1980s and early 1990s, we can find another model of Freedom Education by looking at one elementary school, the Banded Peak Public School in the Rockyview school division in Canada, a school just outside of the city of Calgary, Alberta. The idea was to try to make modern digital computer technology and robotics ubiquitous in the school. The physical structure was architecturally designed with banks of computers in a circle out in the hallway. Whenever a child needed to access the computer, and that was up to the child, they would simply run out into the hallway and jump up to a chair with a computer in front of it. This is drastically different from traditionally approaches of how computers were integrated into the classroom. Typically, a computer or perhaps a few of them were located at the back of a classroom. Occasionally the teacher would assign a computer related task to the students and one at a time they would have to approach the computer, or the few, at the back of the room to engage in their teacher assigned task. Undoubtedly something was learned by this, but not very much. The unique approach 
in Banded Peak enabled the entire school to quickly become computer literate and the teachers who tolerated the degree of freedom which this presupposed were wildly rewarded with interested, knowledgeable and inquiring students.

All of these examples in this section suggest that the enactivist characterrization of how we relate to our environment, and so learn with it, by it as well as for it is also a characterization of how we might best conceive our learning through freedom in our actions and our thoughts. The Buddhist seeking enlightenment, the child in A.S. Neill's school, the hole in the wall experiment in which uneducated children played with a computer and learned to use it, the breaking away from rigid rules and creating new games are all examples both of enactivism in action and of freedom education.

One may still wonder how Freedom Education relates to enactivism as compared to other philosophical stances such as constructivism. The most important thing, we argue, is that enactivist grounded Freedom Education assumes that the learner and her environment are in constant interaction, transforming one another. The learner is not merely "constructing" her world but is already embedded in a world that is changing in part because she herself is involved in the world and is herself changing. This is the essence of enactivism, but is also the precondition for freedom education in the sense that one is not constructing a world solely through intentional action but is acting freely and finds that oneself and one's world are themselves transforming/transformed and developing. This implies that one's body is in the world of one's doing and that one's mental life is also part of the world just as one's body is. The virtual world, as we emphasized in the beginning of this paper, interacts with us primarily through our senses and our minds, but is part of that environment that is not only partly shaping us but is also being shaped by us as we interact with it. Our relationship to that virtual world is not primarily through the many modes of the body as our everyday interaction with the world is, but it is just as intense and important.

There is, of course, something of a puzzle in the enactivist picture of how we relate to our environment as it tends to suggest that the normal mode is largely unstructured and unconstrained. We argue that, from the enactivist point of view, the normative world is part of that grand background or world in which a learner acts and lives. As all these examples demonstrated, the learner is chiefly transformed herself by "the largely tacit normative structure" without changing it very much at any one time and in the process picks up the essence of the normative world. It is definitely not a matter of "fixed knowledge, fixed approaches, fixed abilities and dead end education." For the enactivist or for the supporter of freedom education, the possibility is always there that something radically new can occur in the relationship between the world and the learner much like in the rugby example. The 
emphasis therefore, is not on instruction, but rather on mutual coordination between our mind, body, and the world that provide the main tenets of freedom education.

\section{What Sets Freedom Education Apart?}

There are two things which we emphasize in Freedom Education that set it apart from other traditional educational beliefs. The first is that it is possible through such an approach to learn anything which our species is capable, culturally, of doing now. But second, and equally important, it promotes the creating and learning of things which nobody can yet do but which are within the realm of possibility. And, of course, we wish to encourage both of these human accomplishments as a standard result of education in general.

Creation and innovation: three aspects constitute the basic tenets of freedom education: (1) the learning of all the important things that our species has historically discovered, mastered and catalogued, (2) to offer constant attention to the possibility of the development, or the creation, of new ways of going about old things, and (3) the possibility of ways of going about completely new things. The first aspect is about learning existing knowledge, which is what our current educational systems are all about. The second and third aspects, however, set freedom education apart from other forms of education. Let us clarify the second and third aspects by discussing some examples from games. Lawn tennis began from a variation of "Real" or royal tennis in France, but as England had lots of lawns it was played out of doors on the grass. The game initially would have consisted of three basic strokes: a simple, flat forehand, a simple flat single-handed backhand and a simple underhanded serve. But someone, we do not know who, decided that an overhand serve was possible and tried it out. It wasn't against the rules and it clearly permitted an advantage to the server if skill could be gained at it, though it was more difficult than a simple underhanded serve. Thus a new development, and indeed a dominant one, occurred for the game of tennis. Today the best servers tend to win all of their own games and usually dominate the score.

We can also look at the creative developments in a team sport such a rugby football which is the precursor of Canadian and American football. Many believe that William Webb Ellis whom we mentioned before, born in 1823, with "fine disregard for the rules of football as played in his time took the ball in his arms and ran with it, thus originating the distinctive feature of the Rugby football game” (Willian Ellis n.d. para. 12). According to the Wikipedia, in 1870s, the unofficial story has it that a challenge game was played between two universities, McGill and Harvard, in Montreal and the Canadians were driven back to their own end. A Canadian player, following Webb Ellis's lead 
with a fine disregard for the rules, catching a lateral pass instead of kicking it, threw it down the field and the referee judged that the ball was in play where it landed. Subsequently when the ball was thrown down field players on the same team as the thrower would start out "on side" and try to catch the ball, thus originating the forward pass which dominates the Canadian and the American versions of what was relatively recently referred to as "rugby football" in North America today. The Americans embraced the "forward pass” right away but the Canadians still considered it illegal until 1929.

In both of these examples while the "new" action was not already recognized by the norm of the culture of the game, it was instantly recognizable as a possibility permitted by the context of the game and ultimately became a standard part of it. This sort of possibility is the central notion behind freedom education, in which we believe that the future we face as a species is such that we must constantly be connecting with our contexts and developing them as the needs of the future require an indefinite number of "Webb Ellis" like moves for our species to survive and prosper. Unlike some of the more recent thinkers, such as Erneling (2010), who put little emphasis on creativity, we consider it to be the central feature of the kind of education to which we aspire for all.

The story involving the Inuit of Labrador at Gander during the Second World War exemplifies the creativity of Freedom Education. This anecdote is from the father of one of us who served in air force intelligence and air traffic control at that time at Gander. During that time, Inuit of Labrador were brought to repair aircraft engines at the Gander airbase, the busiest airport on the planet at that time as it was involved in handling the protections of the convoys of boats to Britain from North America that had to pass through Nazi submarine patrols. The Inuit, who could not read English and had no training in aircraft engines, were able to repair sophisticated aircraft engines. Apparently, their own "Freedom Education" practices were crucial in their possessing this knack, which enabled them to creatively solve new problems.

In Freedom Education, innovation and creativity, instead of the traditional basic academic subjects, are placed at a premium to facilitate students' emotional and physical well-being and intellectual abilities for independent judgment. Accordingly, self-actualization and self-understanding are two aspects being promoted. At the center of Freedom Education is the encouragement of exploration, puzzle-solving, as well as playful and spontaneous work-all of which are important for creation and self-renewal. Our central interest is on what is possible and potential, instead of making learners vulnerable prisoners to existing knowledge. 


\section{What Freedom Education Is Not}

But what kinds of education do not count as "freedom" education? Essentially, almost all of our historical and traditional approaches to education, especially formal education, are outside the bounds of what we wish to argue for. For example, in the ordinary classroom or in university instruction worldwide we primarily depend on students listening to the teacher's lecture and students, if they are able, taking notes. An exam will follow based on the lecture. To be sure we can learn a great deal this way. But what we learn is in the context of fixed knowledge, fixed approaches, fixed abilities and dead end education.

At the present time, smartphones, fantastically powerful handheld computers connected to the vast resources of the internet, are being confiscated in for fear that the children will text one another or check in with their friends on social networking sites. This is clearly just the wrong approach to handling the fact that now nearly everybody has their own personal computer in their hand. Practically any learning task can be augmented with the use of the available applications, of which there are now thousands and thousands. But for this we require an understanding of freedom education and what it can do. Robotics kids learn from playing Robotics freely.

How would an enactivist "freedom education" differ from traditional education? Imaging this extreme version of traditional education: a child sits at a desk with a book opened to a specific page in a room with blank walls. She follows the teacher's instruction on a typical task like add up the numbers on the page. The child has nobody to talk to other than the teacher. Adding more students to the room will turn this to a typical classroom. In contrast to such a traditional approach, in freedom education, emphasizing both the child's powers and the environment, the child has an active teacher, active classmates both of whom she may communicate with, access to the internet with infinite possibilities and freedom to interact with them all as she sees fit. While there are some constraints in the sense that we expect there will still be a curriculum to be explored, the child's exploration of that curriculum will be indefinitely varied.

In this paper, we have borrowed some of Erneling's ideas to establish our argument against current educational systems, consequently proposing freedom education based on enactivism. It is important, therefore, for us to clarify how freedom education differs from Erneling's (2010) discursive education. Although we agree with much of Erneling's criticism of Piaget's theory and the infantilization of education, our proposed Freedom Education differs significantly from Erneling's (2010) discursive education. For Erneling:

All learning... is a discursive undertaking, cognitive change is always a social process in which both the form it takes and the content involved are culturally and historically varied. Learning and cognitive development involve the domestication, not infantilisation, of the learner. Natural enabling conditions 
are always involved, but the longer learning proceeds the less important these become...Acquiring a language is the most important precondition for taking part in symbolic activities, especially in schooling. But schooling also involves other skills, such as the ability to ascribe beliefs to others and meta-cognition, the second order ability to reflect on and criticize one's own and others' cognitive activities both publicly and privately...This involves the awareness of one's own beliefs in relation to the norms and standards set and agreed to by teachers with institutional authority. In this important sense, what is private and individual is secondary...School is in a sense the discursive activity par excellence. (172)

This long quotation paints the picture of discursive education as proposed by Erneling (2010). Although she has never explicitly described what discursive education is, her discussion apparently indicates that such discursive education offers a picture heavily weighted toward the teacher as the essential environment in the educational enterprise. Freedom education, we argue, is different from discursive education in two important ways. First, in freedom education, both teachers and important other speakers, as part of the environment, play a crucial role in learning. In addition, the freedom education world includes physical, social, cultural aspects of the environment. Therefore, what is individual, private, innate, social, cultural, public are all equally important. Unlike discursive education, which considers what is private and individual secondary, in freedom education, individual factors are placed at the same level of importance as social and cultural ones, with no hierarchy.

Secondly, discursive education considers the symbolic in the context of human discourse, mainly the teacher talking with the students, to be primary and more important the more sophisticated the student is as a speaker of their common language. Freedom education differs from discursive education in that teacher talk or using language to communicate is not the necessarily the only or the primary way for people to learn. For example, Inuit children learn to build kayak by watching their parents making a kayak from materials like sealskin, bones and sinew sewn. They may do this at various ages from say two to ten or fifteen. The children need not talk with the parents at all although they could ask about the process. But in the end the child can manage to build a kayak her or himself. The Hole in the Wall project provides another example for people to learn what Erneling (2010) refers to as "abstract" knowledge or school subjects like chemistry or technology. This project demonstrates that children can learn various subjects from playing and interacting with a computer without any help from any adult. They even learn a new language, e.g. English, from playing with a computer.

Finally, the child herself is engaged in creative activity with respect to a much wider world. This world includes not only the social and cultural environment the child situated, but also the physical and virtual world she resides. She 
enacts and interacts with such social, cultural world where physical and virtual spaces are intertwined, from which she learns.

\section{Recommendations to establish a learning world of freedom education}

We have discussed various examples of freedom education, from ancient Buddhist education, to Inuit people learning to build a kayak, Mitra's hole in the wall studies, to current students in Canada learning schools subjects. These examples demonstrate that freedom education leads to students' greater understanding. To summarize, we have the following recommendations for those who wish to transform a traditional classroom into one of freedom in the sense we mean.

1. The learning world of freedom education should contain rich stimuli with multiple sensory modalities that inspire students' curiosity to explore freely and intentionally. The learning process should also encourage and promote the use of bodily actions that are conceptually congruent with the knowledge being learned to enhance students' understanding (Black et al. 2012).

2. This learning world should also have built in opportunities, in enactivist terms "affordances" and "constraints," that are carefully crafted with the intention to enable learners to progress towards the possible learning goals in their own time and in their own way. The goals and the processes of learning themselves are not predetermined, but rather negotiated between the learner and her or his world along the way.

3. The inseparability among our mind, body, and the environment suggests the importance of bodily movement in cognition (Li et al. 2010). Consequently, the learning world can facilitate students' comprehension by encouraging students' direct experience of a phenomenon through activities like acting it out with their own body and then moving towards a more abstract understanding (Black et al. 2012). Similarly a child might act out with his or her own mind in the manner that many are engaging in during their recovery from strokes that the discovery of the astonishing plasticity of the brain.

4. Motivation and emotions should be taken into account when designing a learning world of freedom education. Motivation always has an emotional component, but motivation is of two basic kinds, external and intrinsic or internal. In Freedom Education we wish to emphasize intrinsic or internal motivation since the emotional component is always positive and strong. Thus we offer freedom of interaction with the environment for the learner who is both determining her or his goals and developing her or 
his own approaches to the achievement of those goals in the context of the environment.

5. Creativity and innovative skills are placed at a premium when considering freedom education. Learning is definitely not a matter of fixed knowledge, fixed approaches, fixed abilities and at the fixed time. The main tenets of freedom education, rather, are about promoting and encouraging free explorations and innovative ways of learning so that one can best adjust to the world she or he is situated in.

Although we describe these general guidelines for creating a learning world of freedom education, we stress that freedom education grounded in enactivism does not prescribe particular forms of instruction. Freedom education is based on a systematic and ideationally driven approach for educators that uses the theoretical assumptions that underlie enactivism and is exemplified by a number of educational practices that have never been collected together before to understand human cognition and direct the establishment of the learning environment.

In conclusion, we believe that the enactivist proposition is a true autonomous theoretical proposition with a promising future. The above discussion with ample examples of freedom education grounded in enactivism demonstrates that enactivism can offer a coherent and holistic research framework for cognition and beyond.

\section{References}

Baerveldt, C., \& Verheggen, T. 1999. Enactivism and the experiential reality of culture: Rethinking the epistemological basis of cultural psychology. Culture \& Psychology 5(2): 183-206.

Bateson, G. 1972. Steps to an ecology of mind. NY: Ballentine Books.

Black, J., Segal, A., Vitale, J., \& Fadjo, C. 2012. Embodied cognition and learning environment design. D. Jonassen \& S. Land, eds. Theoretical Foundations of Learning Environments (2nd ed.: 198-223. New York: Routledge: Taylor \& Francis Group.

Black, J., Turner, T., J., \& Bower, G. H. 1979. Point of view in narrative comprehension, memory and production. Journal of Verbal Learning and Verbal Behavior, 18: 187-198.

Capra, F. 1996. The web of life: A new synthesis of mind and matter. London: Harper Collins.

Capra, F. 2002. The hidden connections: A science for sustainable living. London: Haper Collins.

Castronova, E. 2007. Exodus to the Virtual World: How Online Fun is Cahning Reality. New York: Palgrave MacMilland. 
Chomsky, N. 1966. Cartesian Linguistics: A Chapter in the History of Rationalist Thought. New York: Harper \& Row.

Davis, B., Sumara, D., \& Luce-Kapler, R. 2000. Engaging minds: Learning and teaching in a complex world. Mahwah, NJ: Lawren Erlbaum Associates.

Davis, B., Sumara, D., \& Luce-Kapler, R. 2008. Engaging minds: Changing teaching in complex times. 2nd ed.. Mahwah, NJ: Lawren Erlbaum Associates.

Dede, C. 2008. A Seismic Shift in Epistemology. EDUCAUSE Review, 43(3), 80-81.

Diodge, N. 2007. The Brain That Changes Itself: Stories of Personal Triumph from the Frontiers of Brain Science. NY: Penguin Group.

Economy of Second Life. n.d.. Wikipedia Retrieved Oct. 30, 2013, from http://en.wikipedia.org/wiki/Economy_of_Second_Life

Erneling, C. 2010. Towards discursive education: Philosophy, technology and modern education. Cambridge: Cambridge University Press.

Fenwick, T. 2000. Expanding conceptions of experiential learning: A review of the five contemporary perspectives on cognition. Adult Education Quarterly, 50(4): 243273.

Henrikson, J. U. 2011. The growth of social media: An infographic. Search Engine Journal. Retrieved from http://www.searchenginejournal.com/the-growth-ofsocial-media-an-infographic/32788/

Jenkins, H., Clinton, K., Purushotma, R., Robison, A., \& Weigel, M. 2006. Confronting the challenges of participatory culture: Media education for the 21st century: 66 . Washington, DC: The John D. and cathering MacArthur Foundation.

Johnson, M. 1989. Personal practical knowledge series: Embodied knowledge. curriculum Inquiry, 19(4): 361-377.

Lamb, A., \& Readhead, Z. 1992. The New Summerhill - A. S. Neill. London: Penguin Books.

Learning. n.d.. Wikipedia. Retrieved from http://en.wikipedia.org/wiki/Learning

Li, Q., Clark, B., \& Winchester, I. 2010. Instructional Design and Technology Grounded in Enactivism: A Paradigm Shift? British Journal of Educational Technology, 41(3): 403-419.

Maturana, H. R., \& Varela, F. J. 1980. Autopoiesis and cognition: The realization of the living. Dordrecht, Holland: D. Reidel Publishing Company.

Maturana, H. R., \& Varela, F. J. 1987. The tree of knowledge: The biological roots of human understanding. Boston: Shambhala.

Merleau-Ponty, M. 1964a. The primacy of perception and other essays. Evanston, IL: Northwestern Universit Press.

Merleau-Ponty, M. 1964b. The primacy of perception and other essays. Evanston, IL: Northwestern Universit Press.

Michie, M. 2004, April. Teaching sciece to Indigenous students: Teachers as culture broker or is it something else? Paper presented at the National Association for Research in Science Teaching, Vancouver, Canada. 
Minecraft (Producer. 2013. Minecraft Statistics. Retrieved from https://minecraft.net/stats

Mitra, S., \& Dangwal, R. 2010. Limits to self-organising systems of learning - The Kalikuppam experiment. British Journal of Educational Technology, 41(5): 672688.

Mitra, S., Dangwal, R., Chatterjee, S., Swati Jha, Bisht, R. S., \& Kapur, P. 2005. Acquisition of computing literacy on shared public computers: Children and the 'Hole in the Wall' Australasian Journal of Educational Technology, 21(3): 407-426.

Mitra, S., \& Rana, V. 2001. Children and the Internet: Experiments with minimally invasive education in India. British Journal of Educational Technology, 32(2): 221232.

Neill, A. S. n.d.. wikipedia. Retrieved from http://en.wikipedia.org/wiki/A._S._Neill

Piaget, J. 1967. Biology and knowledge. Edinburge: Edinburgh University Press.

Piaget, J. 1980. The psychogenesis of knowledge and its epistemological significance. P. Piattelli-Palmarini, ed. Language and Learning: The Debate Between Jean Piaget and Noam Chomsky. Cambridge, MA: Harvard University Press.

Piattelli-Palmarini, M. 1994. Ever since language and learning: Afterthoughts on the Piaget-Chomsky debate. Cognition \& emotion, 50: 315-346.

Plato. 1981. Five Dialogues (G.M.A. Grube, Trans.. Indianapolis: Hackett Publishing Co. Inc.

Popper, K. 1978. Three Worlds. Paper presented at the The Tanner Lecture on Human Values, Michigan: University of Michigan.

http://tannerlectures.utah.edu/lectures/documents/popper80.pdf

Reid, D. 1995. Enactivism Retrieved Nov. 20, 2006, from http://plato.acadiau.ca/courses/educ/reid/enactivism/EnactivismDef.html

Second Life. 2013. Wikipedia. Retrieved from http://en.wikipedia.org/wiki/Second_Life cite_note-nwn.blogs.com.2Fnwn.2F2009.2F03.2Fmillion.html-24

Skinner, B. F. 1974. About bahaviorism. NY: Random House.

Varela, Thompson, E., \& Rosch, E. 1991. The embodied mind: Cognitive science and human experience. Cambridge, MA.: Massachusetts Institute of Technology Press.

Willian Ellis. n.d.. Wikipedia. Retrieved from http://en.wikipedia.org/wiki/William_Webb_Ellis

Winn, W. 2006. Functional contextualism in context: A reply to Fox. Educational Technology Research \& Development, 54(1): 55-59.

World of Warcraft (Producer. n.d., Oct. 27, 2013. Wikipedia Retrieved from http://en.wikipedia.org/wiki/World_of_Warcraft 